\title{
Seasonal Dependency of Tropical Precipitation Change under Global Warming $\mathscr{O}$
}

\author{
YU-FAN GENG \\ Physical Oceanography Laboratory, Institute for Advanced Ocean Studies, Ocean University of China and Qingdao National \\ Laboratory for Marine Science and Technology, Qingdao, China \\ SHANG-PING XIE \\ Scripps Institution of Oceanography, University of California, San Diego, La Jolla, California \\ XiAO-TONG ZHENG AND CHUAN-YANG WANG \\ Physical Oceanography Laboratory, Institute for Advanced Ocean Studies, Ocean University of China and Qingdao National \\ Laboratory for Marine Science and Technology, Qingdao, China
}

(Manuscript received 17 January 2020, in final form 4 July 2020)

\begin{abstract}
Tropical precipitation change under global warming varies with season. The present study investigates the characteristics and cause of the seasonality in rainfall change. Diagnostically, tropical precipitation change is decomposed into thermodynamic and dynamic components. The thermodynamic component represents the wet-get-wetter effect and its seasonality is due mostly to that in the mean vertical velocity, especially in the monsoon regions. The dynamic component includes the warmer-get-wetter effect due to the spatial variations in sea surface temperature (SST) warming, while the seasonality is due to that of the climatological SST and can be largely reproduced by an atmospheric model forced with the monthly climatological SST plus the annual-mean SST warming pattern. In the eastern equatorial Pacific where the SST warming is locally enhanced; for example, rainfall increases only during the March-May season when the climatological SST is high enough for deep convection. To the extent that the seasonality of tropical precipitation change over oceans arises mostly from that of the climatological SST, the results support the notion that reducing model biases in climatology improves regional rainfall projections.
\end{abstract}

\section{Introduction}

Tropical precipitation drives the large-scale atmospheric circulation and is important to global and regional climate. Under global warming, the change in tropical precipitation is associated with the atmospheric circulation, leading to regional climate change (Xie et al. 2015) and great impacts on human society and economy. The tropical precipitation change is mainly attributed to two factors (Seager et al. 2010; Bony et al. 2013): the thermodynamic change due to the increase in water vapor and the atmospheric circulation change (the dynamic response) (Held and Soden 2006; Xie et al. 2010; Chadwick et al. 2013).

Supplemental information related to this paper is available at the Journals Online website: https://doi.org/10.1175/JCLI-D-20-0032.s1.

Corresponding author: Shang-Ping Xie, sxie@ucsd.edu
The thermodynamic component of precipitation change is tied to the climatological precipitation and circulation, increasing in regions/seasons of surface wind convergence (Chou and Neelin 2004; Held and Soden 2006; Chou et al. 2009). This relationship between the climatology and change of precipitation is known as the wet-get-wetter mechanism. By contrast, the dynamic response of precipitation is associated with the changes in both strength and spatial distribution of atmospheric circulation. The strength change is directly linked to the slowdown of mean circulation under global warming (Held and Soden 2006; Vecchi et al. 2006; Vecchi and Soden 2007; Tokinaga et al. 2012; Ma et al. 2012), while the circulation shift is mostly due to the spatially patterned SST warming, known as the warmer-get-wetter mechanism (Xie et al. 2010). The latter mechanism argues that the mean ocean warming pattern regulates the precipitation change over tropical oceans, with increased rainfall in regions of SST warming greater than the tropical mean and vice versa. In coupled model 
projections, the dynamic response due to the weakening mean circulation largely offsets the thermodynamic change (Chadwick et al. 2013). As a result, the warmer-get-wetter mechanism becomes important for the annual-mean tropical precipitation change (Xie et al. 2010).

Previous studies have investigated the seasonal variation of tropical rainfall change under global warming (Sobel and Camargo 2011; Huang et al. 2013; Kent et al. 2015; Lazenby et al. 2018; Lan et al. 2019). Huang et al. (2013) suggested that for the zonal-mean seasonal cycle of tropical precipitation change, the wet-get-wetter effect becomes important. By using a precipitation decomposition method (Chadwick et al. 2013), however, Kent et al. (2015) suggested that the seasonal variation in the horizontal distribution of tropical rainfall change is closely related to the circulation spatial shift term that mainly represents the warmer-get-wetter effect. Therefore, it is still unclear what controls the seasonal variation in spatial distribution of tropical precipitation change.

The purpose of the present study is to investigate the mechanisms for seasonal variations in tropical rainfall change in response to global warming, specifically whether the seasonality of climatological SST or that of SST warming is more important. By designing a set of experiments and using a diagnostic method of precipitation change decomposition, our study aims to investigate the characteristics of each component and its contribution to the seasonality of tropical precipitation change.

The rest of the paper is organized as follows. Section 2 describes the experimental design and the decomposition method as well as the data used in this study. Section 3 presents the annual-mean and seasonal-mean tropical precipitation change under global warming. Section 4 shows the contributions of different components to the seasonality of tropical precipitation change. Section 5 is a summary with discussions.

\section{Data and methods}

\section{a. Atmospheric general circulation model}

The Community Atmosphere Model (CAM) is the atmospheric component of the Community Earth System Model (CESM). We use the CAM, version 4 (CAM4) for experiments, which shares the same deep convection parameterization (Zhang and McFarlane 1995) with CAM5. Patterns of mean tropical precipitation in the two models are similar (Xie et al. 2012; Chen and Dai 2019), indicating that skills in simulating mean tropical precipitation of CAM4 and CAM5 are comparable. The comprehensive description of CAM4 can be found in Neale et al. (2010). We choose a horizontal $1.9^{\circ} \times 2.5^{\circ}$ grid ("f19_f19") with 26 vertical sigma levels.
We carry out four experiments for comparison. The control run, called AMIP, is forced by the observed monthly mean SST and sea ice concentration. In the experiment AMIP4K, we impose a spatially uniform SST increase (SUSI) of $4 \mathrm{~K}$ superimposed on the observed monthly climatological SST. The SST increase is also constant in season. In the experiment AMIPFuture, we impose the spatially patterned SST increase (SPSI) derived from the multimodel-mean CMIP3 quadruple $\mathrm{CO}_{2}(1 \%$ to $4 \times)$ simulation. The SST increase varies by month. In the last experiment, called AMIPFuture annual-mean $\triangle$ SST (shortened to AMIPFAM), we set the imposed SST increase as the annual mean of SST change in AMIPFuture, so it is spatially variable but constant in time. All runs last for 22 years (from 1979 to 2000). The results of the last 20-yr mean (1981-2000) are analyzed.

Previous studies (Huang 2014; Kent et al. 2015; Zhou et al. 2018) demonstrate that the atmospheric general circulation models (AGCMs) can well reproduce the response of tropical precipitation in coupled GCMs. Chadwick et al. (2014) show a weak precipitation response to the direct $\mathrm{CO}_{2}$ effect over tropical oceans, supporting the AGCM reconstruction of the centuryscale pattern of tropical precipitation change. Thus, we use the AGCM runs to analyze tropical precipitation response to different SST warming patterns in our study.

\section{b. $A M I P$}

To test our result of the circulation response to uniform warming, we analyze 12 Atmospheric Model Intercomparison Project (AMIP) experiments in the output of phase 5 of the Coupled Model Intercomparison Project (CMIP5) archive (Table 1): the AMIP control run and the AMIP4K. The AMIP control run is forced by the observed SST and the AMIP4K is forced by the observed SST plus a spatially uniform SST warming of $4 \mathrm{~K}$. All model outputs are interpolated onto a common $2.5^{\circ} \times$ $2.5^{\circ}$ grid, and only the first-member run (r1i1p1) of each model is analyzed.

\section{c. Decomposition of precipitation change}

Based on the moisture budget equation in Trenberth and Guillemot (1995) and Seager et al. (2010), precipitation change can be approximated as follows (Huang et al. 2013; Long et al. 2016):

$$
\Delta P=\frac{1}{\rho_{w} g}(\bar{\omega} \Delta q+\Delta \omega \bar{q}),
$$

where $P, \rho_{w}, \omega$, and $q$ are precipitation, the density of water, upward vertical velocity, and specific humidity, respectively. The overbar denotes the present climatology 
TABLE 1. List of 12 AMIP models from CMIP5 used in this study.

\begin{tabular}{lc}
\hline \hline Model acronym & Expansion \\
\hline BCC-CSM1.1 & Beijing Climate Center (BCC), Climate \\
CanESM2 & System Model (CSM), version 1.1 \\
& Second Generation Canadian Earth \\
System Model \\
Community Climate System Model \\
(CCSM), version 4 \\
CNRM-CM5 & Centre National de Recherches \\
& Météorologiques Coupled Global \\
& Climate Model, version 5 \\
FGOALS-g2 & Flexible Global Ocean-Atmosphere- \\
& Land System Model grid point, ver- \\
& sion 2 \\
HadGEM2-ES & Hadley Centre Global Environment \\
& Model, version 2, Earth System \\
IPSL-CM5A-LR & L'Institut Pierre-Simon Laplace (IPSL) \\
& Coupled Model, version 5A, coupled \\
& with NEMO, low resolution \\
IPSL-CM5B-LR & IPSL Coupled Model, version 5B, coupled \\
& with NEMO, low resolution \\
MIROC5 & Model for Interdisciplinary Research on \\
& Climate 5, version 5 \\
MPI-ESM-LR & Max Planck Institute Earth System Model \\
& (MPI-ESM), low resolution \\
MPI-ESM-MR & MPI-ESM, medium resolution \\
MRI-CGCM3 & Meteorological Research Institute \\
& Coupled Atmosphere-Ocean General \\
&
\end{tabular}

and $\Delta$ denotes change under global warming. For tropical precipitation, it is a good approximation to choose $\omega$ as 500-hPa pressure velocity and $q$ as surface specific humidity (Held and Soden 2006; Huang et al. 2013; Huang 2014; Long et al. 2016). Here we multiply the 500-hPa pressure velocity by -1 to make $\omega$ positive upward. Horizontal moisture advection and the residuals have been neglected.

The precipitation response to global warming can be diagnostically decomposed into thermodynamic and dynamic components (Emori and Brown 2005; Seager et al. 2010; Chou and Lan 2012; Bony et al. 2013; Chadwick et al. 2013). Based on Eq. (1), we decompose the $\Delta P$ into thermodynamic component $\left(\Delta P_{t}, \bar{\omega} \Delta q\right)$ and dynamic component $\left(\Delta P_{d}, \Delta \omega \bar{q}\right)$. The SST pattern effect is estimated by subtracting the AMIP4K from the AMIPFuture (scaled by the tropical-mean $\Delta$ SST) (Huang et al. 2013). The term $\Delta P$ under global warming (AMIPFuture - AMIP) can now be decomposed further:

$$
\Delta P=\Delta P_{t}+\Delta P_{d}=\Delta P_{t}+\Delta P_{d}^{U}+\Delta P_{d}^{\mathrm{AMP}}+\Delta P_{d}^{\mathrm{SP}} .
$$

Here we divide the dynamic component into three parts (Table 2): the SUSI effect $\Delta P_{d}^{U}$ (AMIP4K - AMIP), the annual-mean SST pattern effect $\Delta P_{d}^{\mathrm{AMP}}$ (AMIPFAM -
AMIP4K), and the seasonally varying SST pattern effect $\Delta P_{d}^{\mathrm{SP}}$ (AMIPFuture - AMIPFAM).

Chadwick et al. (2013) decomposed the dynamic effect into components due to the circulation weakening and shift. The circulation weakening component is obtained by regressing the change in mass flux against the mean, opposing the thermodynamic effect on rainfall change. We use a different decomposition method by using additional AMIP simulations. Here, the dynamic effect is decomposed into three subcomponents induced by uniform warming, the annual-mean warming pattern, and the seasonally varying warming pattern, respectively. We will show that the dynamic subcomponent induced by uniform warming does not follow a simple linear relationship with the thermodynamic component. Our method further isolates the effects of the annual mean and seasonal variation of SST change.

\section{Tropical precipitation change under global warming}

First, we analyze the change in annual-mean tropical precipitation under global warming (Fig. 1). Consistent with previous studies (Xie et al. 2010; Chadwick et al. 2013; Huang 2014), rainfall mainly increases in the tropical Pacific, the northern Indian Ocean, and the equatorial Atlantic with a maximum in the equatorial central Pacific (Fig. 1a). We then decompose the total rainfall change $(\Delta P)$ into the thermodynamic $\left(\Delta P_{t}\right.$, Fig. 1c) and dynamic $\left(\Delta P_{d}\right.$, Fig. 1b) components. The thermodynamic component $\Delta P_{t}$ shows positive anomalies in the South Pacific convergence zone (SPCZ) and the intertropical convergence zone (ITCZ), and also over the Maritime Continent, central Africa, and South America (Fig. 1c). The dynamic component $\Delta P_{d}$ predominantly shows positive rainfall change over the equatorial central Pacific, corresponding to the El Niñolike SST warming pattern (Fig. 1b). Note that $\Delta P_{d}$ is quite different from $\Delta P_{t}$, mainly in the ITCZ and SPCZ and also over the Maritime Continent. We further decompose $\Delta P_{d}$ into rainfall changes induced by SUSI $\left(\Delta P_{d}^{U}\right.$; Fig. 1f $)$, the annual-mean SST pattern $\left(\Delta P_{d}^{\mathrm{AMP}}\right.$; Fig. 1e), and the seasonally varying SST pattern $\left(\Delta P_{d}^{\mathrm{SP}}\right.$; Fig. 1d) effects. Overall, the last effect $\left(\Delta P_{d}^{\mathrm{SP}}\right)$ is very weak. In central Africa and South America, the positive $\Delta P_{t}$ is mainly offset by $\Delta P_{d}^{U}$ (Fig. 1f) whereas in the ITCZ and SPCZ the positive $\Delta P_{t}$ is partially offset by $\Delta P_{d}^{\mathrm{AMP}}$ (Fig. 1e). More importantly, the positive peak of $\Delta P$ in the equatorial central Pacific is contributed by $\Delta P_{d}^{\mathrm{AMP}}$ (Fig. 1e). The spatial pattern of annual-mean $\Delta P$ is more strongly related to $\Delta P_{d}$ (spatial correlation $R=$ $0.58)$ than to $\Delta P_{t}(R=0.24)$. Overall, $\Delta P_{d}$ contributes more to the spatial distribution of annual-mean $\Delta P$, 
TABLE 2. List of dynamic subcomponents of $\Delta P_{d}$ (SUSI is spatially uniform SST increase.)

\begin{tabular}{lcc}
\hline \hline $\begin{array}{l}\text { Subcomponents } \\
\text { of } \Delta P_{d}\end{array}$ & Component name & Decomposition method \\
\hline$\Delta P_{d}^{U}$ & SUSI $\Delta P_{d}$ & AMIP4K - AMIP \\
$\Delta P_{d}^{\mathrm{AMP}}$ & Annual-mean pattern $\Delta P_{d}$ & AMIPFAM - AMIP4K \\
$\Delta P_{d}^{\mathrm{SP}}$ & Seasonal pattern $\Delta P_{d}$ & AMIPFuture - AMIPFAM \\
\hline
\end{tabular}

suggesting that the warmer-get-wetter effect dominates the spatial pattern of annual-mean precipitation change over tropical oceans in a warming climate (Xie et al. 2010).

In June-August (JJA), $\Delta P$ shows robust positive anomalies in the Northern Hemisphere and relatively weak changes in the Southern Hemisphere (Fig. 2a). Contributed by the thermodynamic component $\Delta P_{t}$, rainfall mainly increases in the Asian monsoon region and the ITCZ (Figs. 2a,c). Rainfall also increases in the equatorial central Pacific due to the dynamic component $\Delta P_{d}$ (Figs. 2a,b). The $\Delta P_{d}$ is mainly due to $\Delta P_{d}^{U}$ and $\Delta P_{d}^{\mathrm{AMP}}$, while $\Delta P_{d}^{\mathrm{SP}}$ has a relatively small magnitude across the tropics. $\Delta P_{d}^{U}$ largely cancels out $\Delta P_{t}$ in the Indian Ocean and over land (Figs. 2c,f). The $\Delta P_{d}^{\mathrm{AMP}}$ mainly follows the SST warming pattern due to the warmer-get-wetter mechanism, showing a positive peak in the equatorial central Pacific and negative anomalies over the Maritime Continent and SPCZ (Fig. 2e).

In December-February (DJF), $\Delta P$ is mainly positive over the ocean near the equator (Fig. 3a). The SUSI term $\left(\Delta P_{d}^{U}\right)$ largely offsets $\Delta P_{t}$ (Kent et al. 2015), especially over South Africa, South America, and the Maritime Continent (Figs. 3c,f). Both in JJA and DJF,
$\Delta P_{d}^{\mathrm{AMP}}$ shows positive rainfall changes over the equatorial central Pacific (Figs. 2e and 3e) and $\Delta P_{d}^{\mathrm{SP}}$ has small magnitudes in the tropics (Figs. 2d and 3d), indicating that the seasonal variation of SST warming makes a weak contribution to that of tropical rainfall change.

Overall, tropical rainfall response to SST warming features two major characteristics. First, the response over the ocean mainly coincides with the SST pattern response (warmer-get-wetter effect) and is largely captured in the annual-mean SST pattern $\left(\Delta P_{d}^{\mathrm{AMP}}\right)$. Second, the SUSI response $\left(\Delta P_{d}^{U}\right)$ tends to compensate the thermodynamic response $\left(\Delta P_{t}\right)$, especially over land and monsoon regions during local summer. Next, we investigate the origin of the seasonality in tropical rainfall change.

\section{Contributions of different components to the seasonality of tropical precipitation change}

\section{a. Thermodynamic component $\left(\Delta P_{t}\right)$}

The spatial distribution of the thermodynamic component $\left(\Delta P_{t}\right)$ is dominated by the spatial pattern of the
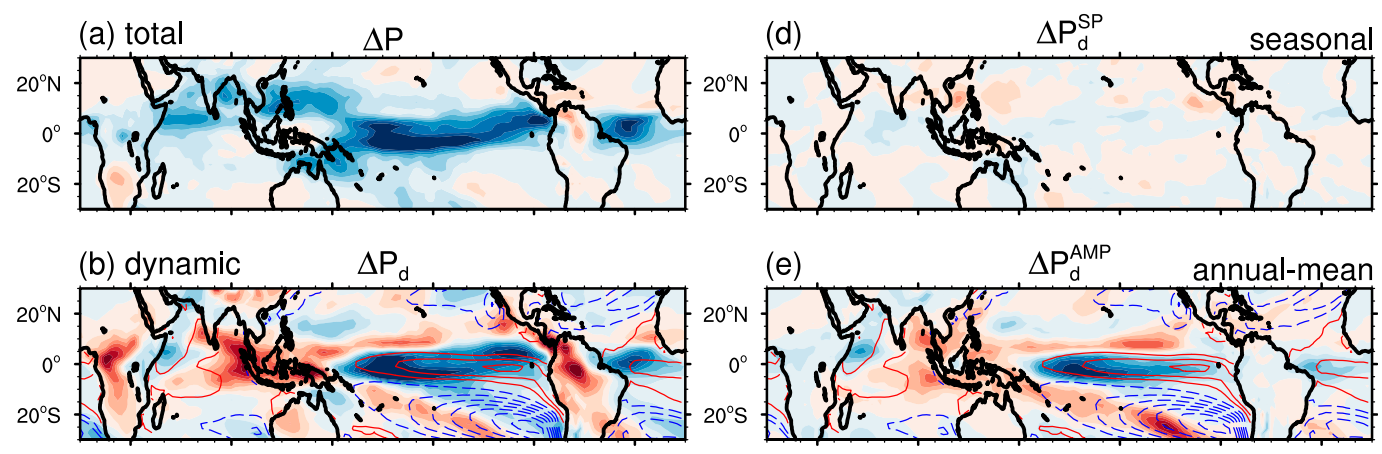

(c) thermodynamic $\Delta \mathrm{P}_{\mathrm{t}}$

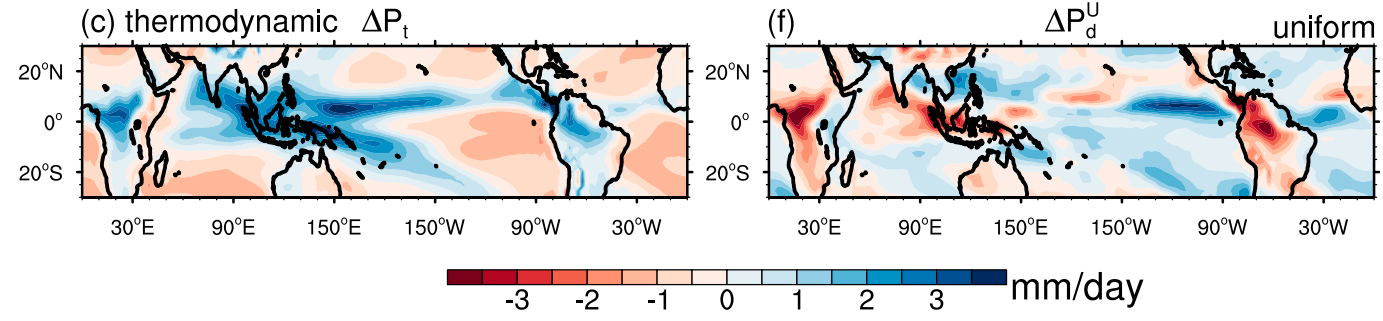

FIG. 1. Annual-mean $\Delta P$ under global warming (shading): (a) $\Delta P$, (b) $\Delta P_{d}$, (c) $\Delta P_{t}$, (d) $\Delta P_{d}^{\mathrm{SP}}$, (e) $\Delta P_{d}^{\mathrm{AMP}}$, and (f) $\Delta P_{d}^{U}$. The red (blue) solid contours in (b) and (e) show the positive (negative) deviation of the annual-mean $\Delta$ SST from the tropical mean (with a $0.3^{\circ} \mathrm{C}$ interval; values between $-0.2^{\circ}$ and $+0.2^{\circ} \mathrm{C}$ are omitted). 
(a) total

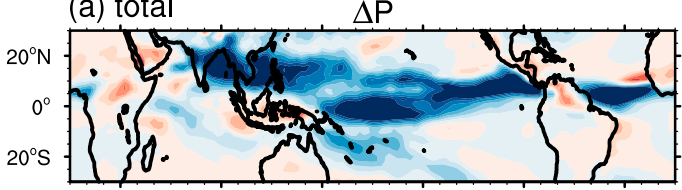

(b) dynamic

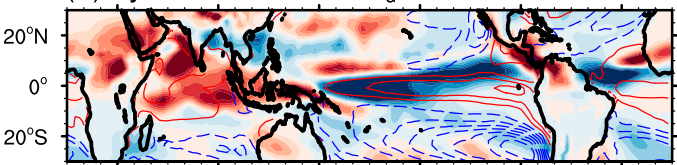

(c) thermodynamic $\Delta \mathrm{P}_{\mathrm{t}}$

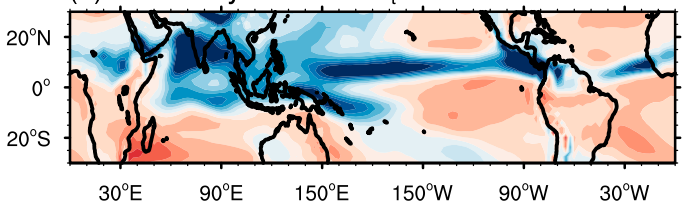

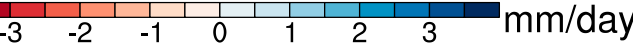

FIG. 2. Seasonal-mean $\Delta P$ in JJA under global warming (shading): (a) $\Delta P$, (b) $\Delta P_{d}$, (c) $\Delta P_{t}$, (d) $\Delta P_{d}^{\mathrm{SP}}$, (e) $\Delta P_{d}^{\mathrm{AMP}}$, and (f) $\Delta P_{d}^{U}$. The red (blue) solid contours show the positive (negative) deviation of the seasonal-mean $\Delta$ SST in JJA from the tropical mean, the deviation of the annual-mean $\Delta$ SST from the tropical mean, and the seasonal deviation of $\Delta \mathrm{SST}$ in (b), (e), and (d), respectively (with a $0.3^{\circ} \mathrm{C}$ interval; values between $-0.2^{\circ}$ and $+0.2^{\circ} \mathrm{C}$ are omitted).

mean upward vertical velocity $(\bar{\omega})$ because of the relatively uniform distribution of surface specific humidity $(\bar{q})$ and its change $(\Delta q)$ in the tropics (Huang 2014; Long et al. 2016), reflecting the wet-get-wetter effect. Both $\Delta P$ and $\Delta P_{t}$ (or mean vertical velocity $\bar{\omega}$ ) tend to be above the annual mean in the summer hemisphere, especially in the monsoon regions, and below the annual mean in the winter hemisphere [(a)-(c) of Figs. 1-3]. It suggests that the strong seasonality of rainfall change is associated with $\bar{\omega}$.

For any location, $\bar{\omega}$ can be written as

$$
\bar{\omega}=\langle\bar{\omega}\rangle+\bar{\omega}^{*},
$$

where the angle brackets and the asterisk denote the zonal mean and deviation, respectively. The maximum
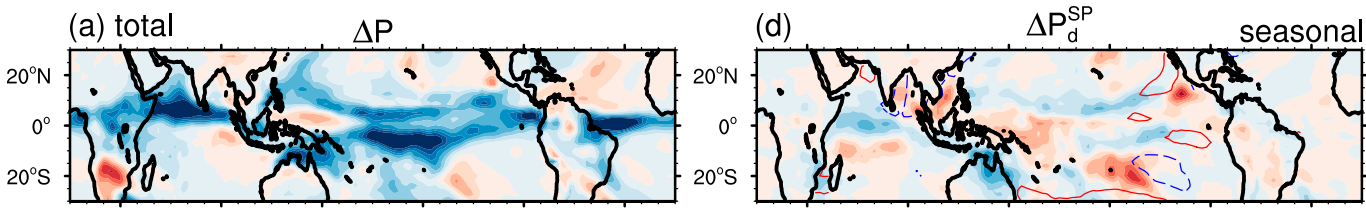

(b) dynamic $\quad \Delta \mathrm{P}_{\mathrm{d}}$

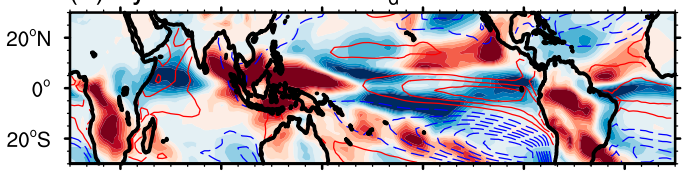

(e)

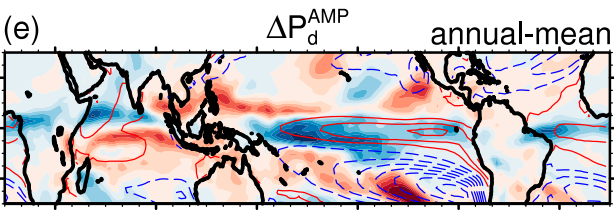

(c) thermodynamic $\Delta \mathrm{P}_{\mathrm{t}}$

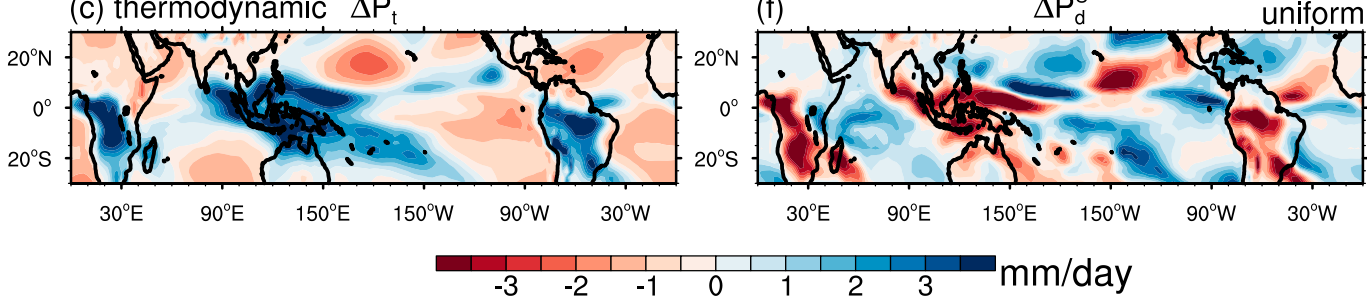

FIG. 3. As in Fig. 2, but for seasonal-mean precipitation change under global warming in DJF. 

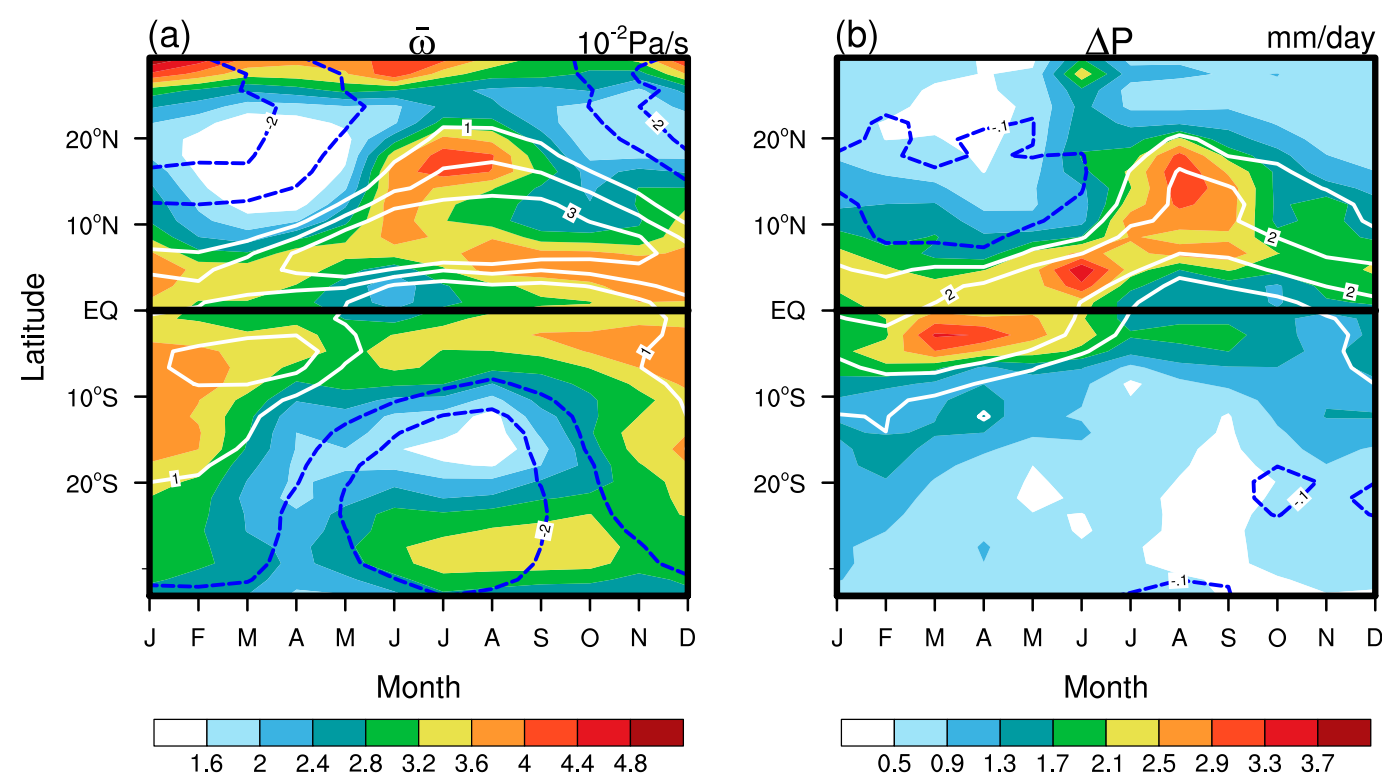

FIG. 4. Zonal mean (contours) and zonal standard deviation (shading) of (a) $\bar{\omega}\left(10^{-2} \mathrm{~Pa} \mathrm{~s}^{-1}\right)$ and (b) $\Delta P$ $\left(\mathrm{mm} \mathrm{day}^{-1}\right.$ ). The solid white lines denote (a) upward $\bar{\omega}$ and (b) positive $\Delta P$ while the dashed blue lines denote (a) downward $\bar{\omega}$ and (b) negative $\Delta P$.

of $\langle\bar{\omega}\rangle$ indicates the migrating ITCZ (white contours in Fig. 4a) and the maximum of the zonal-mean $\Delta P$ follows that of $\langle\bar{\omega}\rangle$ (white contours in Fig. 4b). Huang et al. (2013) suggested that the seasonal cycle of zonal-mean rainfall change is largely attributed to $\langle\bar{\omega}\rangle$. The wet-getwetter effect, however, cannot be extended to apply regionally (Wills et al. 2016).

In the subtropics of the winter hemisphere, due to the robust subsidence of the Hadley cell (blue contours in Fig. 4a), the zonal mean of $\Delta P$ is nearly zero and shows a "dry-get-drier" pattern in $10^{\circ}-20^{\circ} \mathrm{N}$ from December to May approximately (Fig. 4b). In the summer hemisphere, the zonal variation of $\Delta P$ is large (Fig. $4 \mathrm{~b}$ ), corresponding to large $\bar{\omega}^{*}$ (Fig. 4a). In local summer, the zonal-mean $\Delta P$ is also large but not representative of regional rainfall change. In JJA, for example, $\Delta P$ in the summer subtropics $\left(10^{\circ}-20^{\circ} \mathrm{N}\right)$ is confined zonally in the Indo-western Pacific sector (Fig. 2a).

Figure 4 also shows a seasonal delay of zonal mean $\Delta P$ with regard to its climatology $(\bar{P}$; here the seasonal cycle of $\bar{\omega}$ represents that of $\bar{P})$. In the Northern Hemisphere $\left(10^{\circ}-20^{\circ} \mathrm{N}\right), \Delta P$ is positive in the second half of the summer, whereas in the Southern Hemisphere $\left(0^{\circ}-10^{\circ} \mathrm{S}\right)$ the rainfall increase is most pronounced in March-April (the second half of the rainy season). The phase shift can be attributed to a phase delay in $\Delta \omega$ (Dwyer et al. 2014), and further to the seasonality change in SST (Dwyer et al. 2012, 2014). The delayed seasonal cycle in a warmer climate corresponds to a muted response of early season rainfall (e.g., January through June in $10^{\circ}-$ $20^{\circ} \mathrm{N}$; Fig. $4 \mathrm{~b}$ ) and a delay of monsoon onset (Biasutti and Sobel 2009; Seth et al. 2011). Song et al. (2018) explained this seasonal delay from the perspective of the interhemispheric energy contrast.

\section{b. Dynamic component under uniform warming $\left(\Delta P_{d}^{U}\right)$}

In DJF, $\Delta P_{d}^{U}$ induced by spatially uniform SST warming largely cancels out $\Delta P_{t}$ over South Africa, South America, and the Maritime Continent (Figs. 3c,f). In JJA, a robust cancellation takes place in much of the tropical Indian Ocean. However, $\Delta P_{d}^{U}$ and $\Delta P_{t}$ are both positive in the Bay of Bengal, South China Sea, and tropical northwest Pacific (Figs. 2c,f), indicating that $\Delta P_{d}^{U}$ is not a simple cancellation of $\Delta P_{t}$.

To diagnose the large-scale atmospheric circulation (Ma et al. 2012; Ma and Xie 2013; He et al. 2014), we analyze the ensemble mean of $300-\mathrm{hPa}$ velocity potential $(\chi)$ of the AMIP and AMIP4K runs from 12 CMIP5 models. Figure 5 shows that with the upper-level divergence center in the tropical western Pacific and convergence center in the eastern Pacific, the Walker circulation in JJA is stronger than that in DJF. The slowdown of the Walker circulation is apparent in both JJA and DJF (Figs. 5a,b), but the strongest change in velocity potential displaces west of the climatological center of divergence in JJA in the Asian monsoon region. Similar to JJA, a weak westward shift of the velocity potential change relative to the mean also occurs in DJF (Fig. 5b). Thus, the circulation change under uniform warming is not a simple slowdown of the mean circulation. 
(a) JJA

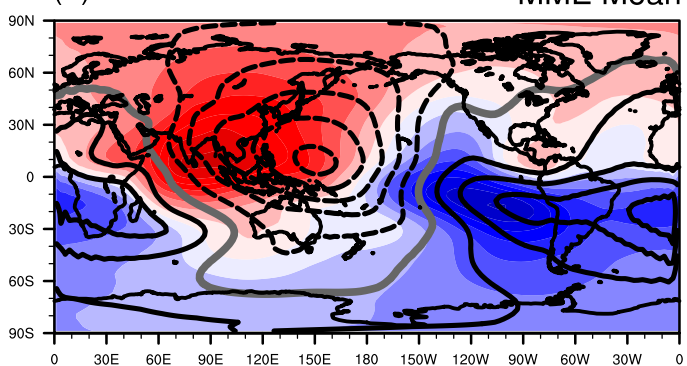

(b) DJF

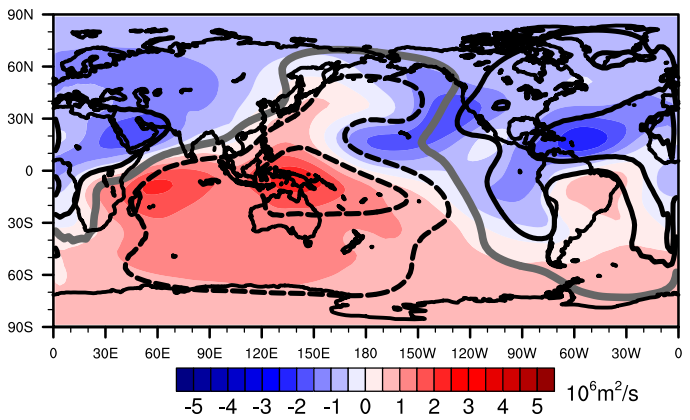

(c) JJA

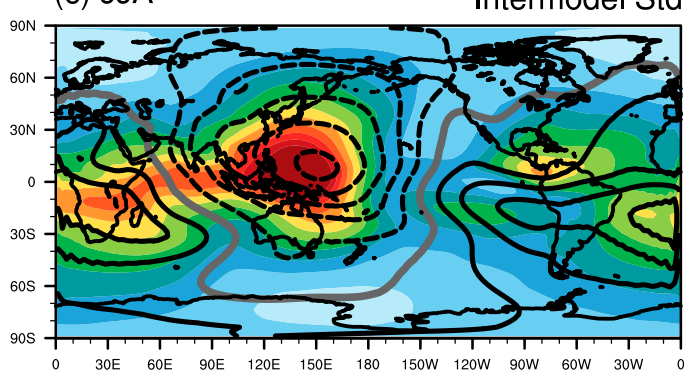

(d) DJF

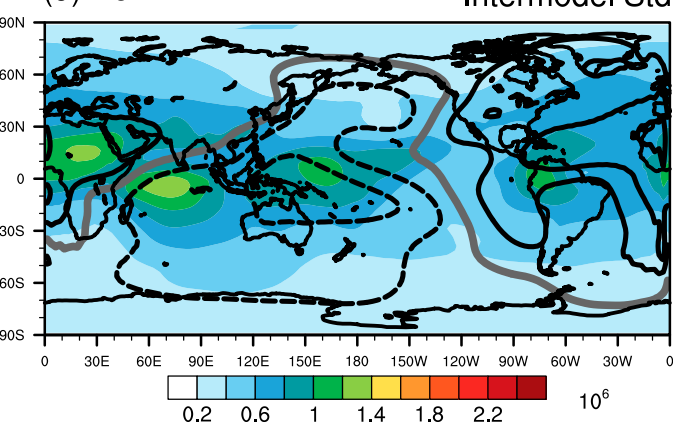

FIG. 5. (a),(b) Multimodel ensemble mean and (c),(d) intermodel standard deviation of the 300-hPa velocity potential change (shading) from AMIP4K-AMIP in (top) JJA and (bottom) DJF. The AMIP climatology is in contours (interval of $1.6 \times 10^{6} \mathrm{~m}^{2} \mathrm{~s}^{-1}$; the zero contour is thickened in gray). The solid (dashed) lines denote positive (negative) velocity potential.

We have also examined the changes in individual CMIP5 models. The westward shift of the change relative to the mean is obvious in most models, except for FGOALS-g2 (see Figs. S1 and S2 in the online supplemental material). The intermodel diversity of the velocity potential change peaks in the tropical northwest Pacific in JJA, roughly in the same region of the maximum upper-level divergence in the present climatology (Fig. 5c). The result in DJF is similar in spatial distribution but weak in magnitude, compared to JJA (Fig. 5d). This indicates that large model uncertainty exists regarding the circulation slowdown and the magnitude or position of the westward shift under global warming. The physical mechanisms for the circulation shift (Ma et al. 2012), however, are still unclear. Previous studies suggested that it is associated with the land-sea contrast in surface warming and specific humidity (Chadwick et al. 2014, 2019; He et al. 2014; Kent et al. 2015). The zonal shift between $\Delta \chi$ and mean $\chi$ in JJA is consistent with positive (negative) $\Delta P_{d}^{U}$ over the Bay of Bengal to the northwest tropical Pacific (the rest of the tropical Indian Ocean to the southwest) (Fig. 2f).

\section{c. Dynamic component under annual-mean SST pattern $\left(\Delta P_{d}^{\mathrm{AMP}}\right)$}

The SST change under global warming features an El Niño-like pattern (contours in Figs. 1-3). The equatorial peak of $\Delta$ SST strengthens slightly in June (Fig. 6a). Away from the equator, $\Delta S S T$ increases in late summer through fall. The seasonal variation of $\Delta$ SST is weak in the tropics (Fig. 6b) but the annual range exceeds $0.4^{\circ} \mathrm{C}$ at $20^{\circ} \mathrm{N}$, a latitude that rainbands of the Asian summer monsoon reach. The climatological SST shows strong seasonality, nearly symmetric about the equator in the deep tropics during March-May (MAM), but is warmer north than south of the equator in other months (Fig. 6c), corresponding to that of climatological precipitation (Fig. 7). Figure 7 shows that the maximum of climatological precipitation in the Northern Hemisphere is in the summer season (JJA), whereas the maximum in the Southern Hemisphere is in MAM due to that of the climatological SST. The strong seasonality of rainfall change and circulation change could be due to that of the climatological SST.

Figure 8a shows a robust anomalous ascent near the equator in the first half of the year under global warming. This is due mainly to the annual-mean $\Delta$ SST (Fig. 8c). The robust anomalous ascent is displaced slightly south of the equator and induces anomalous compensating subsidence north of the equator with anomalous cross-equatorial northerlies (Huang et al. 2013). The $\omega$ responses to uniform warming and seasonal $\Delta$ SST are both weak (Figs. $8 \mathrm{~b}, \mathrm{~d}$ ), indicating that the seasonality of $\Delta \omega$ is dominated by that of climatological SST, rather than $\Delta$ SST. 
(a) Tropical mean $4.48^{\circ} \mathrm{C}$

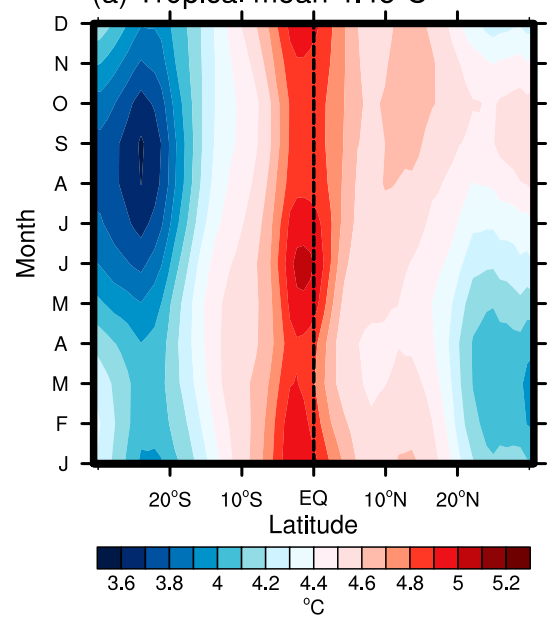

(b)

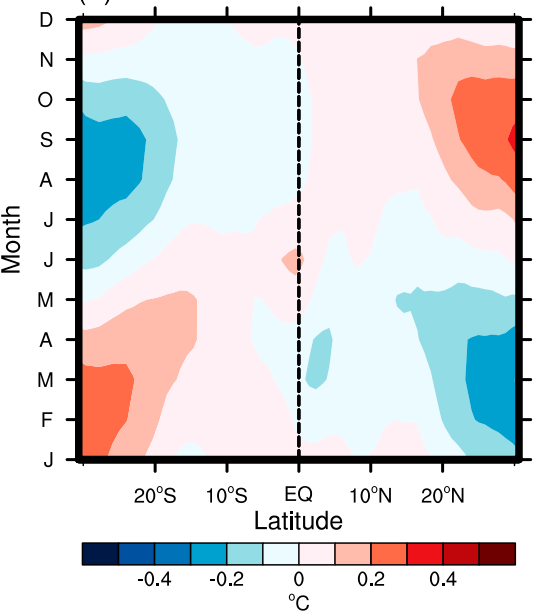

(c)

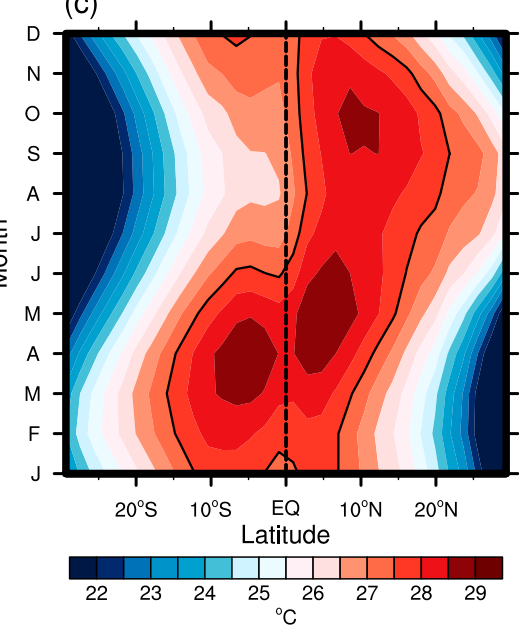

FIG. 6. Zonal-mean seasonal cycle of (a) $\Delta$ SST under global warming, (b) seasonal deviation of $\Delta$ SST from the annual mean under global warming, and (c) the observed monthly mean climatological SST (from 1981 to 2000). Contours in (c) denote the climatological SST of $27.5^{\circ} \mathrm{C}$.

The warmer-get-wetter effect on $\Delta \omega$ and $\Delta P$ can be understood from moist instability change due to $\Delta$ SST and $\Delta q$ (Xie et al. 2010). Over the eastern equatorial Pacific, despite the El Niño-like $\Delta \mathrm{SST}$ and increased $\Delta q$, $\Delta \omega$, and $\Delta P$ are weak in the annual average (Huang 2014). This suggests the crucial role of the climatological SST in modulating the warmer-get-wetter effect. Figure 8c shows that the maximum of $\Delta \omega$ collocates with the positive peak of annual-mean $\Delta$ SST near the equator in the first half of the year. In the second half of the year, however, the anomalous ascent is weak near the equator due to low climatological SSTs. In the present climate, SST above $27.5^{\circ} \mathrm{C}$ is required for large-scale deep convection (Fig. 7; Graham and Barnett 1987). The threshold is approximately $1^{\circ} \mathrm{C}$ higher than the tropical mean SST $\left(\sim 26.5^{\circ} \mathrm{C}\right)$. Since the SST threshold for convection increases in tandem with the tropical mean SST under global warming (Johnson and Xie 2010), we consider the regions where local SST is greater than the threshold of the tropical mean $+1{ }^{\circ} \mathrm{C}$ to be active in deep convection in a changing climate. Figure $8 \mathrm{c}$ shows that the annualmean $\Delta$ SST has a considerable impact on deep convection from January to May, while in the second half of the year, the impact on deep convection is small because of lower climatological SST on the equator.

Figure 9 shows the strong seasonality of $\Delta \omega$ forced by the annual-mean SST pattern. The robust anomalous ascent takes place in the central and eastern equatorial Pacific in MAM (Fig. 9a), while it is confined to the central equatorial Pacific in other seasons (Figs. 9b-d). The robust anomalous ascent in MAM in the eastern equatorial Pacific (Fig. 9a) is due to the seasonal increase of climatological SST that draws the ITCZ closest to the equator. The seasonality of $\Delta \omega$ largely follows the seasonality of the climatological SST, especially in the eastern equatorial Pacific (Fig. 10). Therefore, only when the climatological SST is close to or exceeds the threshold for convection does the warmer-get-wetter effect on rainfall change get turned on.

Figure 11 shows the standard deviation of monthly mean $\Delta \omega$ and $\Delta P$ induced by the annual-mean SST

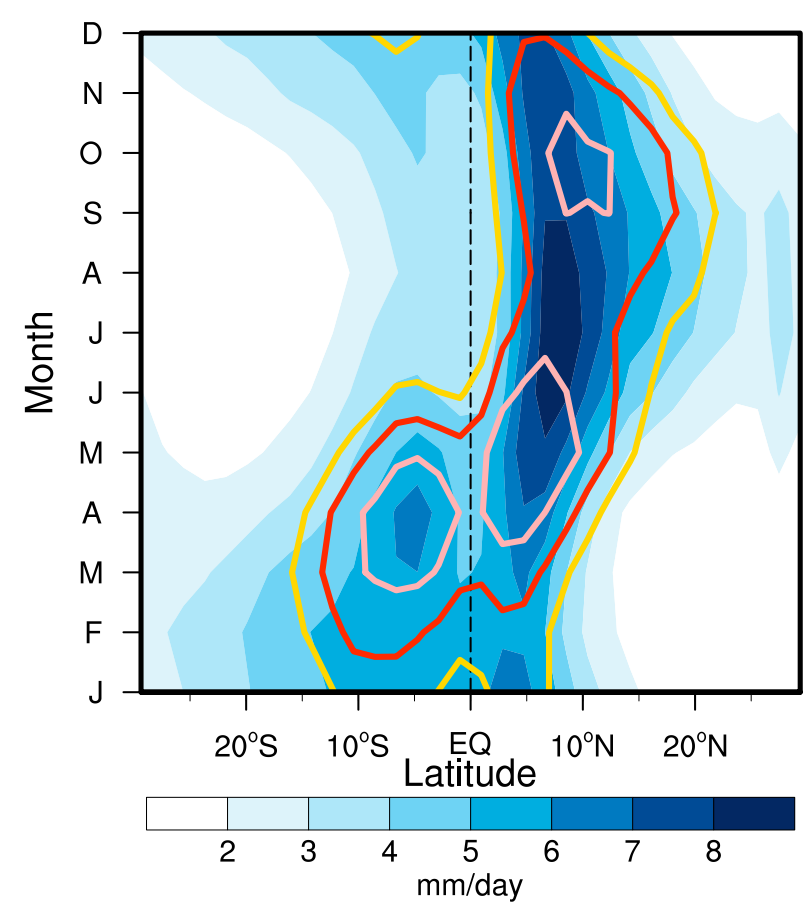

FIG. 7. Zonal-mean seasonal cycle of climatological precipitation $\bar{P}$ (shading). Solid yellow, red, and pink lines denote the $27.5^{\circ}, 28^{\circ}$, and $28.5^{\circ} \mathrm{C}$ isotherms of climatological SST, respectively. 
(a) $\Delta \omega$

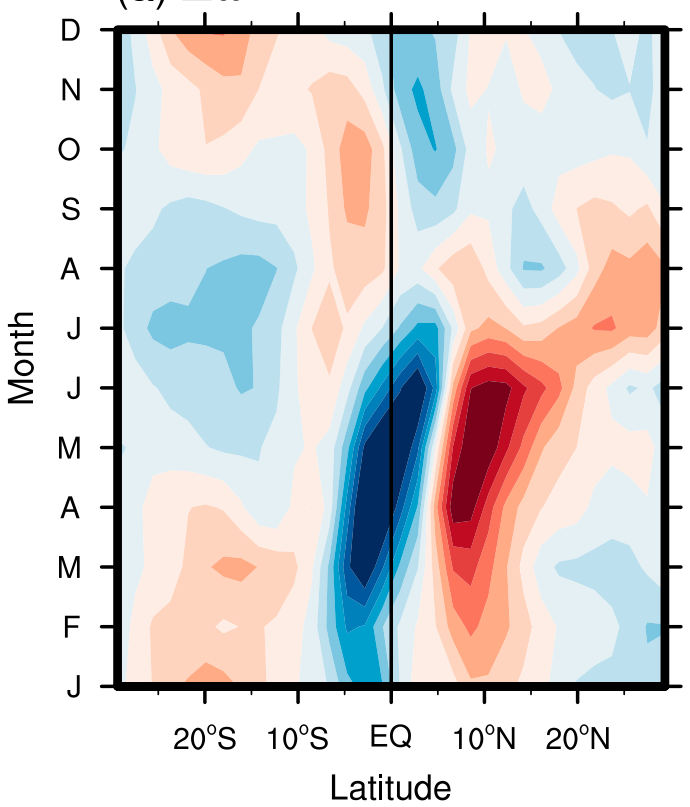

(c) annual-mean pattern $\Delta \omega$

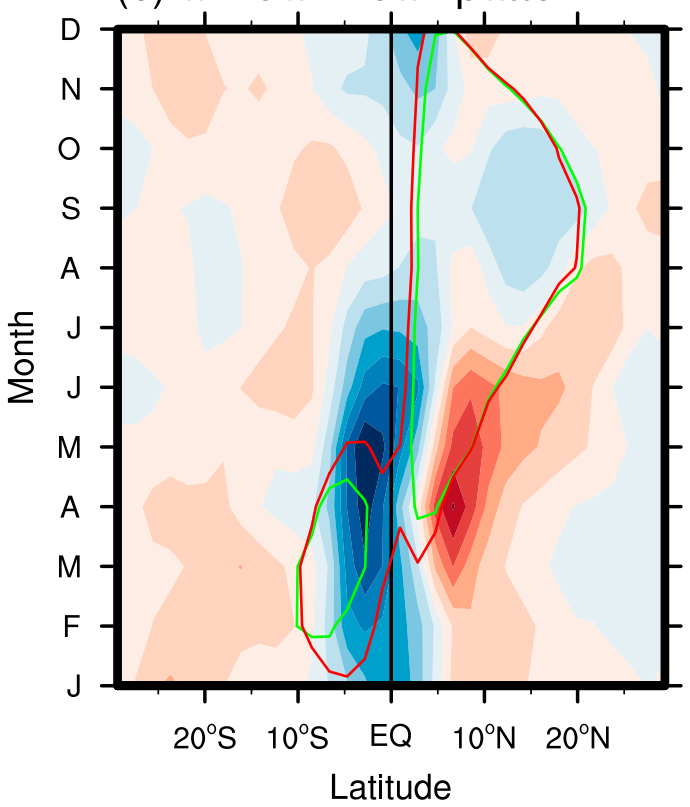

(b) SUSI $\Delta \omega$

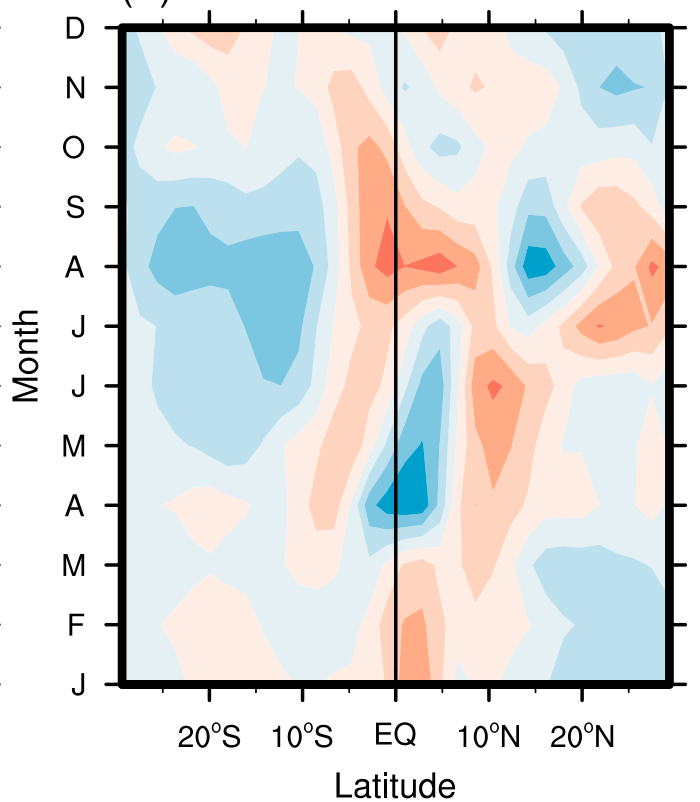

(d) seasonal pattern $\Delta \omega$

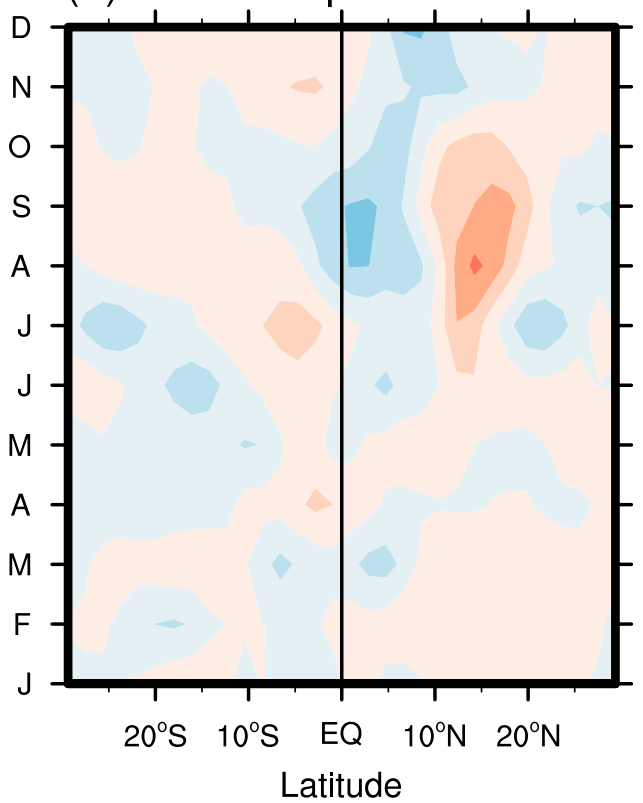

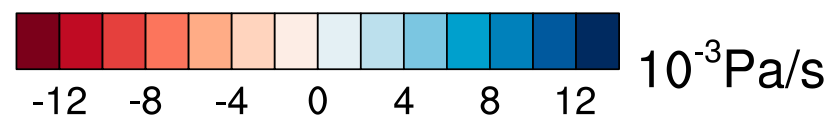

FIG. 8. Zonal-mean seasonal cycle of $\Delta \omega$ in (a) $\Delta P_{d}$, (b) the SUSI effect $\Delta P_{d}^{U}$, (c) the annual-mean SST pattern effect $\Delta P_{d}^{\mathrm{AMP}}$, and (d) the seasonally varying SST pattern effect $\Delta P_{d}^{\mathrm{SP}}$. The green and red solid contours in (c) denote the region of deep convection (the tropical-mean SST $+1^{\circ} \mathrm{C}$ ) in the present and future climatologies, respectively.

pattern effect. In the eastern equatorial Pacific, the seasonal variations of $\Delta \omega$ and $\Delta P$ are large due to the aforementioned effect of the climatological SST seasonal cycle. Both $\Delta \omega$ and $\Delta P$ feature strong seasonal variations in the tropical northwestern Pacific and Asian monsoon region (Fig. 11) where the background seasonal cycle is strong. Enhanced seasonal variance of $\Delta P$ in Fig. 11 resembles the response of an AGCM to an El Niño SST pattern that is kept constant in time (Fig. 5a of Xie and Zhou 2017). All this shows the crucial role of 

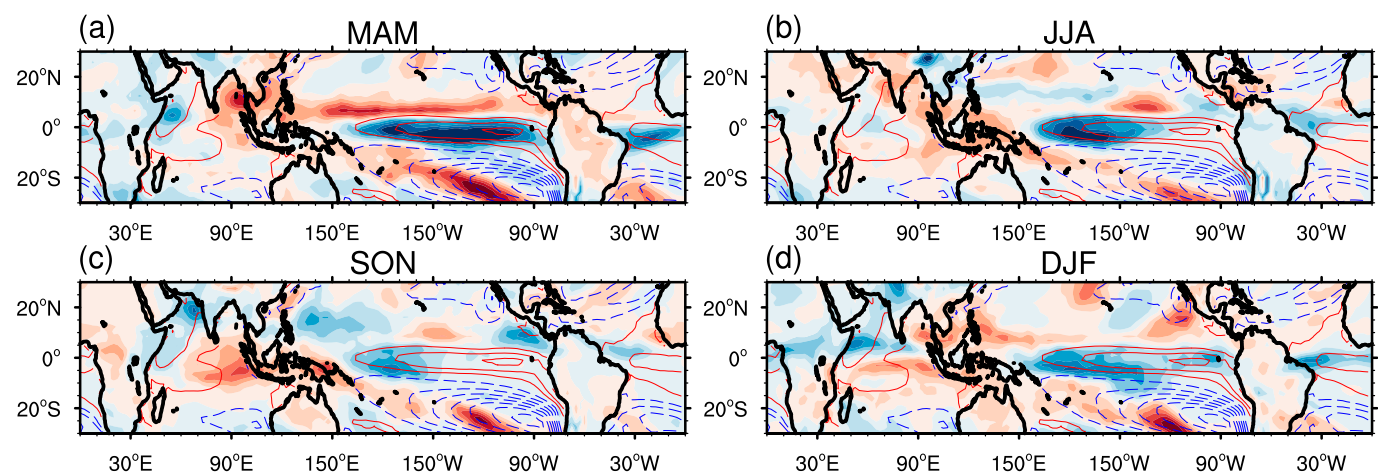

(d)
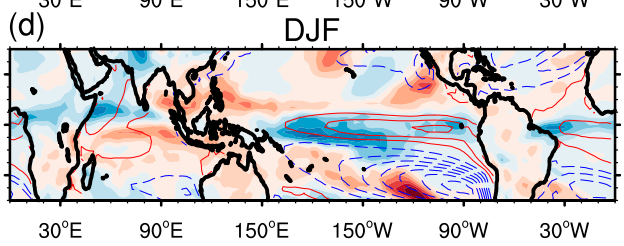

$$
\begin{array}{lll|l|l|lllll}
-30 & -20 & -10 & 0 & 10 & 20 & 30 & 10^{-3} \mathrm{~Pa} / \mathrm{s}
\end{array}
$$

FIG. 9. Spatial patterns of $\Delta \omega$ forced by the annual-mean SST pattern in (a) MAM, (b) JJA, (c) SON, and (d) DJF. The red (blue) solid (dashed) contours are positive (negative) deviation of the annual-mean $\Delta$ SST from the tropical mean (with a $0.3^{\circ} \mathrm{C}$ interval; values between $-0.2^{\circ}$ and $+0.2^{\circ} \mathrm{C}$ are omitted).

climatological SST in determining local convective activity, which can further affect the rainfall change and its seasonality.

The spatially patterned SST warming, especially the equatorial warming peak, causes the ITCZ to contract equatorward (Huang et al. 2013; Zhou et al. 2019). The ITCZ's equatorward shift shows a robust seasonality (Fig. 8a) that can be reproduced with annual-mean $\Delta$ SST (Fig. $8 \mathrm{c}$ ). Thus, the seasonality of the ITCZ contraction is due mostly to that of climatological SST, but not so much to that of SST warming.

\section{Summary and discussion}

We have used AGCM experiments to investigate the mechanisms for the strong seasonal cycle of tropical precipitation change in response to global warming. The precipitation change consists of thermodynamic and dynamic components. We further use model experiments to decompose the dynamic component into three subcomponents due to uniform warming and to the annual mean and seasonal variation of the SST warming pattern, respectively.

The spatial pattern of thermodynamic component is mainly controlled by the mean upward vertical velocity $(\bar{\omega})$, following the wet-get-wetter mechanism. It shows robust positive anomalies in the monsoon regions of the summer hemisphere, consistent with the climatological precipitation. The zonal variation of rainfall change is large in the summer hemisphere and weak in the winter hemisphere, corresponding to that of $\bar{\omega}$. In local summer, the zonal mean is not representative of regional rainfall change.

The dynamic component is due mainly to SUSI and the annual-mean SST pattern, while the effect of seasonally varying SST pattern is small. In addition to the slowdown of the mean circulation, we identify a robust westward shift of 300-hPa velocity potential change from the climatological distribution. The cause of this shift needs further investigation.

The seasonality of $\Delta \omega$ under SPSI is dominated by the seasonal cycle of the climatological SST rather than $\Delta$ SST. Specifically, in the eastern equatorial Pacific, moist instability change induced by annual-mean $\Delta$ SST can only cause robust rainfall and circulation change in MAM when the background SST reaches the annual

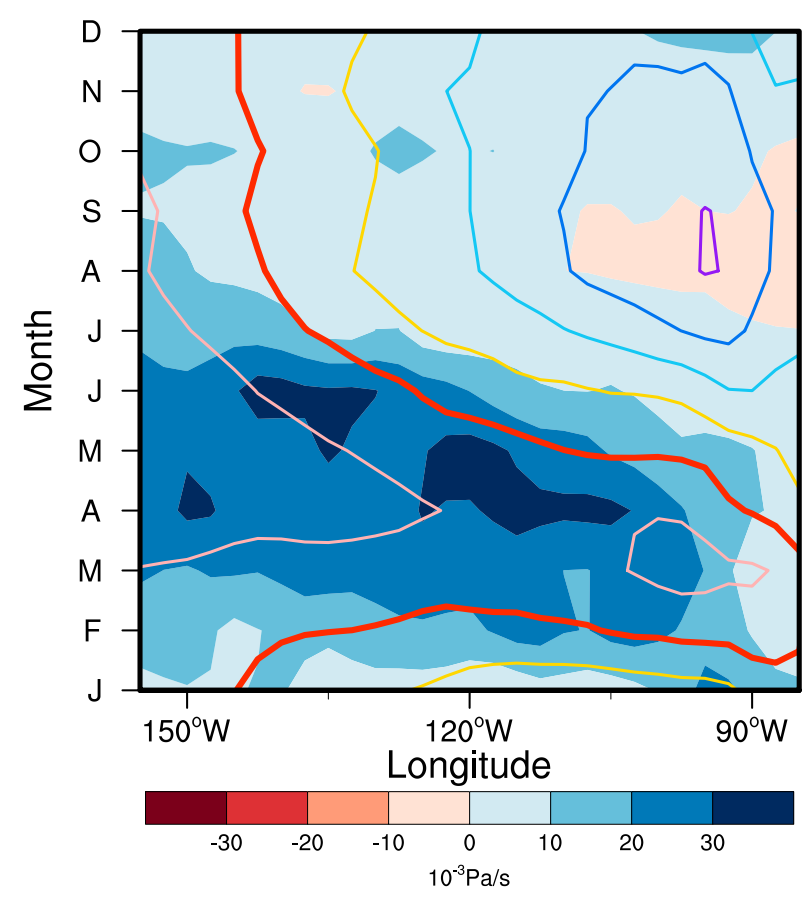

FIG. 10. Seasonal cycle of $\Delta \omega$ in the eastern equatorial Pacific $\left(1^{\circ} \mathrm{S}-1^{\circ} \mathrm{N}\right)$ forced by the annual-mean SST pattern. Contours are the climatological SSTs with a $1^{\circ} \mathrm{C}$ interval. The $26^{\circ} \mathrm{C}$ (red) contours are thickened. 
(a) $\Delta \omega$

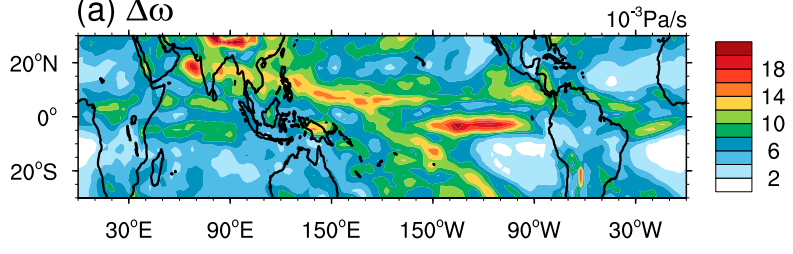

(b) $\Delta \mathrm{P}$

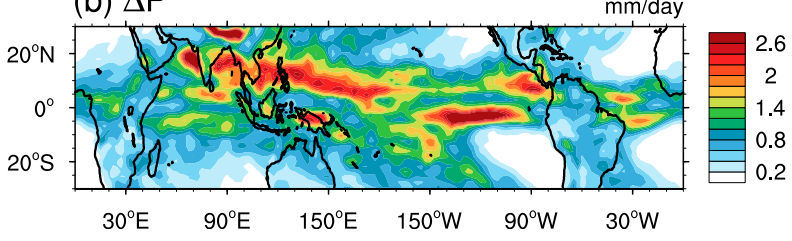

FIG. 11. Spatial patterns of the standard deviation of monthly mean (a) $\Delta \omega$ and (b) $\Delta P$ from the annual mean forced by the annual-mean SST pattern.

peak and allows deep convection to occur. Furthermore, although the equatorward contraction of the ITCZ is driven by the equatorial peak in $\triangle$ SST (Huang et al. 2013; Zhou et al. 2019), its seasonal cycle is mainly due to the strong seasonality of the background SST.

Overall, the seasonal precipitation response to global warming results from a combination of wet-get-wetter and warmer-get-wetter effects (Huang et al. 2013). This study highlights that the climatological seasonal cycle of SST dominates the seasonality of tropical precipitation change by modulating both wet-get-wetter and warmerget-wetter effects.

Projections of precipitation change suffer large intermodel uncertainty and internal variability (Deser et al. 2012; Rowell 2012; Ma and Xie 2013; Long et al. 2016; Chadwick 2016; Lazenby et al. 2018). Our results show that the seasonal cycle of background SST is important for tropical rainfall change. Climate models suffer large biases in climatology (Zhou and Xie 2015), for instance in the ITCZ and the equatorial cold tongue (Li et al. 2016). Such mean biases affect the SST warming pattern (Li et al. 2016; Ying et al. 2019; Seager et al. 2019) and regional rainfall projections (Zhou and Xie 2015; Li et al. 2017). These issues remain to be investigated quantitatively in future studies.

Acknowledgments. We wish to thank three anonymous reviewers for constructive comments. Y.F.G. and C.Y.W. are supported by the National Key Research and Development Program of China (2016YFA0601804 and 2018YFA0605702) and S.P.X. is supported by the National Science Foundation (AGS 1637450). The National Center for Atmospheric Research (NCAR) provided the CESM model. Computational resources were provided by National Supercomputer Centre in Guangzhou (NSCC-GZ), China.

\section{REFERENCES}

Biasutti, M., and A. H. Sobel, 2009: Delayed Sahel rainfall and global seasonal cycle in a warmer climate. Geophys. Res. Lett., 36, L23707, https://doi.org/10.1029/2009GL041303.

Bony, S., G. Bellon, D. Klocke, S. Sherwood, S. Fermepin, and S. Denvil, 2013: Robust direct effect of carbon dioxide on tropical circulation and regional precipitation. Nat. Geosci., 6 , 447-451, https://doi.org/10.1038/ngeo1799.

Chadwick, R., 2016: Which aspects of $\mathrm{CO}_{2}$ forcing and SST warming cause most uncertainty in projections of tropical rainfall change over land and ocean? J. Climate, 29, 2493-2509, https://doi.org/10.1175/JCLI-D-15-0777.1.

— I. Boutle, and G. Martin, 2013: Spatial patterns of precipitation change in CMIP5: Why the rich do not get richer in the tropics. J. Climate, 26, 3803-3822, https://doi.org/10.1175/ JCLI-D-12-00543.1.

— , P. Good, T. Andrews, and G. Martin, 2014: Surface warming patterns drive tropical rainfall pattern responses to $\mathrm{CO}_{2}$ forcing on all timescales. Geophys. Res. Lett., 41, 610-615, https://doi.org/10.1002/2013GL058504.

, D. Ackerley, T. Ogura, and D. Dommenget, 2019: Separating the influences of land warming, the direct $\mathrm{CO}_{2}$ effect, the plant physiological effect, and SST warming on regional precipitation changes. J. Geophys. Res. Atmos., 124, 624-640, https:// doi.org/10.1029/2018jd029423.

Chen, D., and A. Dai, 2019: Precipitation characteristics in the Community Atmosphere Model and their dependence on model physics and resolution. J. Adv. Model. Earth Syst., 11, 2352-2374, https://doi.org/10.1029/2018MS001536.

Chou, C., and J. D. Neelin, 2004: Mechanisms of global warming impacts on regional tropical precipitation. J. Climate, 17, 2688-2701, https://doi.org/10.1175/1520-0442(2004)017<2688: MOGWIO > 2.0.CO;2.

- , and C.-W. Lan, 2012: Changes in the annual range of precipitation under global warming. J. Climate, 25, 222-235, https://doi.org/10.1175/JCLI-D-11-00097.1.

— J. D. Neelin, C. A. Chen, and J. Y. Tu, 2009: Evaluating the "rich-get-richer" mechanism in tropical precipitation change under global warming. J. Climate, 22, 1982-2005, https:// doi.org/10.1175/2008JCLI2471.1.

Deser, C., A. Phillips, V. Bourdette, and H. Y. Teng, 2012: Uncertainty in climate change projections: The role of internal variability. Climate Dyn., 38, 527-546, https://doi.org/10.1007/ s00382-010-0977-x.

Dwyer, J. G., M. Biasutti, and A. H. Sobel, 2012: Projected changes in the seasonal cycle of surface temperature. J. Climate, 25, 6359-6374, https://doi.org/10.1175/JCLI-D-11-00741.1.

,$- \ldots$, and -2014 : The effect of greenhouse gas-induced changes in SST on the annual cycle of zonal mean tropical precipitation. J. Climate, 27, 4544-4565, https://doi.org/10.1175/ JCLI-D-13-00216.1.

Emori, S., and S. J. Brown, 2005: Dynamic and thermodynamic changes in mean and extreme precipitation under changed climate. Geophys. Res. Lett., 32, L17706, https://doi.org/ 10.1029/2005GL023272.

Graham, N., and T. P. Barnett, 1987: Sea surface temperature, surface wind divergence, and convection over tropical oceans. Science, 238, 657-659, https://doi.org/10.1126/science.238.4827.657.

He, J., B. J. Soden, and B. Kirtman, 2014: The robustness of the atmospheric circulation and precipitation response to future anthropogenic surface warming. Geophys. Res. Lett., 41, 26142622, https://doi.org/10.1002/2014GL059435. 
Held, I. M., and B. J. Soden, 2006: Robust responses of the hydrological cycle to global warming. J. Climate, 19, 5686-5699, https://doi.org/10.1175/JCLI3990.1.

Huang, P., 2014: Regional response of annual-mean tropical rainfall to global warming. Atmos. Sci. Lett., 15, 103-109, https:// doi.org/10.1002/asl2.475.

—, S.-P. Xie, K. M. Hu, G. Huang, and R. H. Huang, 2013: Patterns of the seasonal response of tropical rainfall to global warming. Nat. Geosci., 6, 357-361, https://doi.org/10.1038/ngeo1792.

Johnson, N. C., and S.-P. Xie, 2010: Changes in the sea surface temperature threshold for tropical convection. Nat. Geosci., $\mathbf{3}$, 842-845, https://doi.org/10.1038/ngeo1008.

Kent, C., R. Chadwick, and D. P. Rowell, 2015: Understanding uncertainties in future projections of seasonal tropical precipitation. J. Climate, 28, 4390-4413, https://doi.org/10.1175/ JCLI-D-14-00613.1.

Lan, C. W., M. H. Lo, C. A. Chen, and J. Y. Yu, 2019: The mechanisms behind changes in the seasonality of global precipitation found in reanalysis products and CMIP5 simulations. Climate Dyn., 53, 4173-4187, https://doi.org/10.1007/s00382-019-04781-6.

Lazenby, M. J., M. C. Todd, R. Chadwick, and Y. Wang, 2018: Future precipitation projections over central and southern Africa and the adjacent Indian Ocean: What causes the changes and the uncertainty? J. Climate, 31, 4807-4826, https:// doi.org/10.1175/JCLI-D-17-0311.1.

Li, G., S.-P. Xie, Y. Du, and Y. Luo, 2016: Effects of excessive equatorial cold tongue bias on the projections of tropical Pacific climate change. Part I: The warming pattern in CMIP5 multi-model ensemble. Climate Dyn., 47, 3817-3831, https:// doi.org/10.1007/s00382-016-3043-5.

,$- \ldots$ C. He, and Z. Chen, 2017: Western Pacific emergent constraint lowers projected increase in Indian summer monsoon rainfall. Nat. Climate Change, 7, 708-712, https://doi.org/ 10.1038/nclimate3387.

Long, S.-M., S.-P. Xie, and W. Liu, 2016: Uncertainty in tropical rainfall projections: Atmospheric circulation effect and the ocean coupling. J. Climate, 29, 2671-2687, https://doi.org/ 10.1175/JCLI-D-15-0601.1.

Ma, J., and S.-P. Xie, 2013: Regional patterns of sea surface temperature change: A source of uncertainty in future projections of precipitation and atmospheric circulation. J. Climate, 26, 2482-2501, https://doi.org/10.1175/JCLI-D-12-00283.1.

, _— , and Y. Kosaka, 2012: Mechanisms for tropical tropospheric circulation change in response to global warming. J. Climate, 25, 2979-2994, https://doi.org/10.1175/JCLI-D-11-00048.1.

Neale, R. B., and Coauthors, 2010: Description of the NCAR Community Atmosphere Model (CAM 4.0). NCAR Tech. Note NCAR/TN-485+STR, 212 pp., www.cesm.ucar.edu/ models/ccsm4.0/cam/docs/description/cam4_desc.pdf.

Rowell, D. P., 2012: Sources of uncertainty in future changes in local precipitation. Climate Dyn., 39, 1929-1950, https:// doi.org/10.1007/s00382-011-1210-2.

Seager, R., N. Naik, and G. A. Vecchi, 2010: Thermodynamic and dynamic mechanisms for large-scale changes in the hydrological cycle in response to global warming. J. Climate, 23, 4651-4668, https://doi.org/10.1175/2010JCLI3655.1.

—, M. Cane, N. Henderson, D.-E. Lee, R. Abernathey, and H. Zhang, 2019: Strengthening tropical Pacific zonal sea surface temperature gradient consistent with rising greenhouse gases. Nat. Climate Change, 9, 517-522, https://doi.org/ 10.1038/s41558-019-0505-x.

Seth, A., S. A. Rauscher, M. Rojas, A. Giannini, and S. J. Camargo, 2011: Enhanced spring convective barrier for monsoons in a warmer world? Climatic Change, 104, 403-414, https://doi.org/ 10.1007/s10584-010-9973-8.

Sobel, A. H., and S. J. Camargo, 2011: Projected future changes in tropical summer climate. J. Climate, 24, 473-487, https:// doi.org/10.1175/2010JCLI3748.1.

Song, F., L. R. Leung, J. Lu, and L. Dong, 2018: Seasonally dependent responses of subtropical highs and tropical rainfall to anthropogenic warming. Nat. Climate Change, 8, 787-792, https://doi.org/10.1038/s41558-018-0244-4.

Tokinaga, H., S.-P. Xie, C. Deser, Y. Kosaka, and Y. M. Okumura, 2012: Slowdown of the Walker circulation driven by tropical Indo-Pacific warming. Nature, 491, 439-443, https://doi.org/ 10.1038/nature11576.

Trenberth, K. E., and C. J. Guillemot, 1995: Evaluation of the global atmospheric moisture budget as seen from analyses. J. Climate, 8, 2255-2272, https://doi.org/10.1175/ 1520-0442(1995)008<2255:EOTGAM > 2.0.CO;2.

Vecchi, G. A., and B. J. Soden, 2007: Global warming and the weakening of the tropical circulation. J. Climate, 20, 43164340, https://doi.org/10.1175/JCLI4258.1.

, A. T. Wittenberg, I. M. Held, A. Leetmaa, and M. J. Harrison, 2006: Weakening of tropical Pacific atmospheric circulation due to anthropogenic forcing. Nature, 441, 73-76, https://doi.org/10.1038/nature04744.

Wills, R. C., M. P. Byrne, and T. Schneider, 2016: Thermodynamic and dynamic controls on changes in the zonally anomalous hydrological cycle. Geophys. Res. Lett., 43, 4640-4649, https:// doi.org/10.1002/2016GL068418.

Xie, S., H.-Y. Ma, J. S. Boyle, S. A. Klein, and Y. Zhang, 2012: On the correspondence between short- and long-time-scale systematic errors in CAM4/CAM5 for the Year of Tropical Convection. J. Climate, 25, 7937-7955, https://doi.org/10.1175/ JCLI-D-12-00134.1.

Xie, S.-P., and Z.-Q. Zhou, 2017: Seasonal modulations of El Niñorelated atmospheric variability: Indo-western Pacific Ocean feedback. J. Climate, 30, 3461-3472, https://doi.org/10.1175/ JCLI-D-16-0713.1.

—, C. Deser, G. A. Vecchi, J. Ma, H. Y. Teng, and A. T. Wittenberg, 2010: Global warming pattern formation: Sea surface temperature and rainfall. J. Climate, 23, 966-986, https://doi.org/10.1175/2009JCLI3329.1.

_ - and Coauthors, 2015: Towards predictive understanding of regional climate change. Nat. Climate Change, 5, 921-930, https://doi.org/10.1038/nclimate2689.

Ying, J., P. Huang, T. Lian, and H. Tan, 2019: Understanding the effect of an excessive cold tongue bias on projecting the tropical Pacific SST warming pattern in CMIP5 models. Climate Dyn., 52, 1805-1818, https://doi.org/10.1007/s00382-018-4219-y.

Zhang, G. J., and N. A. McFarlane, 1995: Sensitivity of climate simulations to the parameterization of cumulus convection in the Canadian Climate Center general circulation model. Atmos.Ocean, 33, 407-446, https://doi.org/10.1080/07055900.1995.9649539.

Zhou, W., S.-P. Xie, and D. Yang, 2019: Enhanced equatorial warming causes deep-tropical contraction and subtropical monsoon shift. Nat. Climate Change, 9, 834-839, https:// doi.org/10.1038/s41558-019-0603-9.

Zhou, Z.-Q., and S.-P. Xie, 2015: Effects of climatological model biases on the projection of tropical climate change. J. Climate, 28, 9909-9917, https://doi.org/10.1175/JCLI-D-15-0243.1.

,-- G. J. Zhang, and W. Zhou, 2018: Evaluating AMIP skill in simulating interannual variability of summer rainfall over the Indo-western Pacific. J. Climate, 31, 2253-2265, https:// doi.org/10.1175/JCLI-D-17-0123.1. 